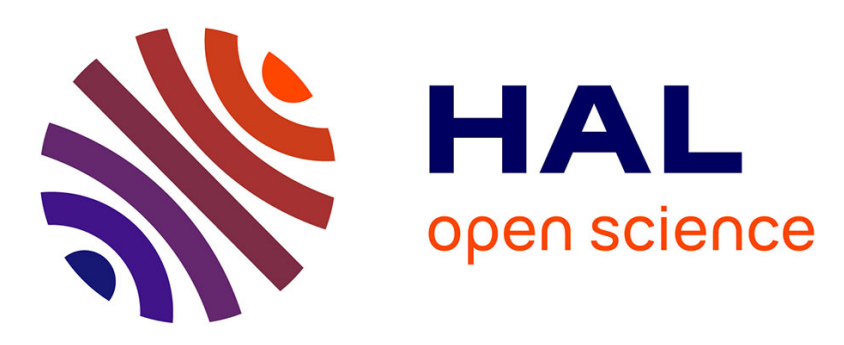

\title{
Cold forming by stretching of aeronautic sheet metal parts
}

Philippe Dal Santo, Guénaël Germain, Serge Boude, Eliane Giraud

\section{To cite this version:}

Philippe Dal Santo, Guénaël Germain, Serge Boude, Eliane Giraud. Cold forming by stretching of aeronautic sheet metal parts. International Journal of Computer Integrated Manufacturing, 2014, 27 (2), pp.129-138. 10.1080/0951192X.2013.800641 . hal-01063176

\section{HAL Id: hal-01063176 https://hal.science/hal-01063176}

Submitted on 11 Sep 2014

HAL is a multi-disciplinary open access archive for the deposit and dissemination of scientific research documents, whether they are published or not. The documents may come from teaching and research institutions in France or abroad, or from public or private research centers.
L'archive ouverte pluridisciplinaire HAL, est destinée au dépôt et à la diffusion de documents scientifiques de niveau recherche, publiés ou non, émanant des établissements d'enseignement et de recherche français ou étrangers, des laboratoires publics ou privés. 


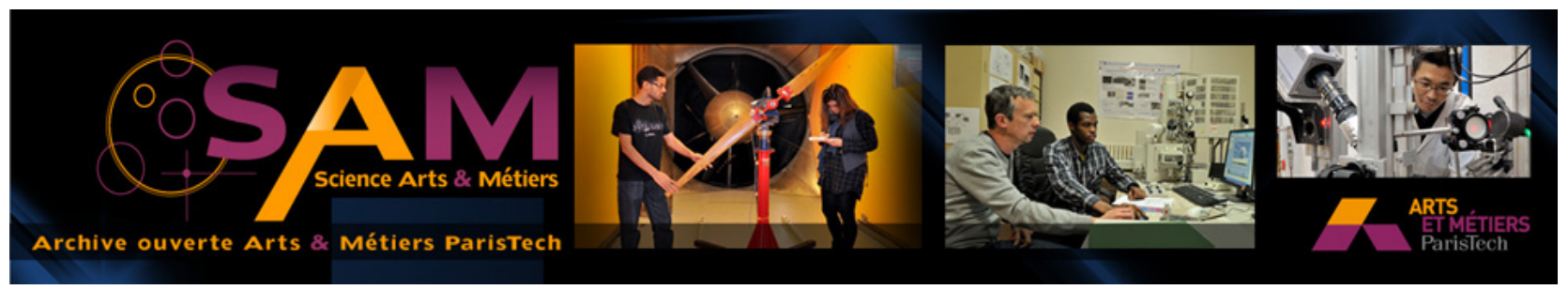

Science Arts \& Métiers (SAM)

is an open access repository that collects the work of Arts et Métiers ParisTech researchers and makes it freely available over the web where possible.

This is an author-deposited version published in: http://sam.ensam.eu

Handle ID: .http://hdl.handle.net/10985/8495

\section{To cite this version :}

Philippe DAL SANTO, Guénaël GERMAIN, Serge BOUDE, Eliane GIRAUD - Cold forming by stretching of aeronautic sheet metal parts - International Journal of Computer Integrated Manufacturing - Vol. 27, n², p.129-138 - 2014 


\title{
Cold forming by stretching of aeronautic sheet metal parts
}

\author{
Philippe Dal Santo, Guénaël Germain*, Serge Boude and Eliane Giraud \\ LAMPA Arts et Métiers ParisTech, Paris, France
}

\begin{abstract}
In this article, the development of an industrial prototype for manufacturing aeronautical fuselage panels is investigated. Deep drawing of large components such as aircraft fuselage panels is not an easy task in terms of dimensional accuracy, reliable material behaviour laws and failure criteria. Hot stretching processes ensure large ductility range of some materials. Nevertheless, when using high-performance aluminium alloys with acceptable low-plastic strain at ambient temperature, cold forming might be employed. A special stretching machine of 40 -ton $(400 \mathrm{kN})$ capability was instrumented and piloted in that way. Typical operations involved in the forming of parts are carried out with a die on which the sheet metal is successively stretched and drawn in several steps. Currently, the shape of the forming tool is directly determined from CAD models of the final sheet geometry without taking into account springback or residual effects. To increase the dimensional accuracy of the final components, a methodology to define the die shape and to control the process is proposed, taking into account the parameters influencing the forming operations. A feedback loop based on digitalised physical geometry and numerical simulation is carried out in order to ensure that the final shape of the sheet will be accurately obtained.
\end{abstract}

Keywords: cold forming; drawing; numerical simulation; stretching; stretching machine; recalibrating

\section{Introduction}

Sheet metal-forming processes are commonly employed in the aeronautic industry to elaborate panels used in aircraft structures. During the last years, numerous works have focused on the study of the process flexibility due to the various kinds of parts involved in aircraft structures. The elaboration of small parts does not exhibit any difficulties since high forces are not necessary. However, the elaboration of large thin-sheet metal parts with maximum shape accuracy and in life reliability is much more complicated: specific machine tools and appropriate processes have to be developed.

In this article, a special stretching machine to manufacture aeronautical fuselage panels is described, as well as its piloting during the forming process. These panels, which have non-developable geometry, are currently obtained by sheet metal drawing. The corresponding forming tools are generally designed without taking into account the springback effects. However, during the last decades, several models have been suggested to take this phenomenon into account. Naceur, Guo, and Ben-Elechi (2008) have established a methodology operating control parameters. Pourboghrat and Chu (1995) have proposed a method, based on analytical formulations, to predict springback during sheet metal undergoing plane strain stretching, bending and unbending deformations. This method was devoted to the prediction of the final shape of parts used in automotive sheet metal stamping operations which exhibit complex forms of material springback. Other authors, such as $\mathrm{He}$ et al. (2010) and Meinders et al. (2008), have also developed methods for the prediction, compensation and optimisation of springback. Aluminium and steel sheets were indeed studied with normal anisotropy and plane strain hypothesis. The numerical results were thus compared to conventional U-shape sheet-forming experiments: an acceptable accuracy was obtained. Nevertheless, this type of formulation cannot be used in the present case (i.e., the forming of aircraft panels) since the plane strain hypothesis is not appropriate to non-developable surfaces. In a similar manner, Ding and Duncan (2004) have shown that a phenomenon of instability can occur in aged steel submitted simultaneously to tension and bending: the spring forward phenomenon. As a result, the sheet metal curvature might be greater than the one used for un-aged strip. This is mainly due to the normal stress redistribution through the sheet thickness during the material ageing which reduces the yield stress after a long time. Despite the use of aluminium alloy in the aircraft industry, this phenomenon is not encountered since the time between the receipt of the sheet and its use is relatively short.

Based on analytical calculations, Yoshida et al. (2005) have suggested a limit fracture criterion as a function of the bending curvature ratio $\frac{t_{0}}{R}$ for three types of aluminium sheets subjected to stretch bending. Chien, Pan, and Tang (2004) have proposed a combined necking and shear localisation analysis to model the failures of two aluminium sheets under biaxial stretching conditions. They have shown that 
the estimated surface failure strains are higher than the failure strains of the forming limit diagrams (FLD) under plane strain stretching conditions. FLD failure predictions must thus be attentively considered. Despite their interesting conclusions, the stretch bending analysis proposed in the two aforementioned papers cannot be applied in the present situation where complex phenomena arise due to contact conditions with a die during stretching, sequential sheet metal stretching and bending by arms of a special machine and bi-curvature of the formed parts.

Consequently, it has been decided to use numerical simulation of the forming process in order to predict the effects of die shape, material and process parameters on the final part shape. The die shape parameters and machine axes motions are defined using the CATIA $^{\circledR}$ CAD system (Dassault Systèmes, Vélizy-Villacoublay, France). The material is modelled using an elastoplastic behaviour law, including plastic anisotropy, which is implemented in the ABAQUS ${ }^{\circledR}$ (Dassault Systèmes) (Hibbitt, Karlsson, Sorensen, Inc. 2011a) finite element analysis package. The methodology involving the shape optimisation of the formed parts is carried out with an instrumented drawing bench, and experiments are compared to numerical simulation results. Tests were performed on a Hufford 50T stretching machine. The material investigated for this study of sheet stretching is a 2024 aluminium alloy for cold forming with a sheet thickness $t_{0}=4 \mathrm{~mm}$. The initial objectives are to design, install and test the equipment (i.e., tools, computer numerical control system (CNC system) and measurement system) in order to form parts by cold stretching and to validate the process for an industrial case. The final objective is to develop an integrated and parametric numerical simulation of the process, exchanging data and procedures between CAD, ABAQUS CAE and the control systems.

\section{Product parameters}

\subsection{Type of panels}

Fuselages of aircraft are structures involving the assembly of several metallic panels with different specific shapes. In
Figure 1, the panel under consideration is shown with the initial flat strip and its final shape (Figure 1a) and the approximate zone where it is assembled on the airplane fuselage (Figure 1b). As shown in the figure, there are many kinds of panel shapes and only one will be studied here.

\subsection{Panel specifications}

The manufactured parts are common fuselage panels defined by the following geometric parameters:

(1) Average dimensions of the parts: $3 \times 0.3 \mathrm{~m}$ with three possible thicknesses (1.6, 2.5 and $5.3 \mathrm{~mm})$.

(2) Primary radius of curvature: $5 \mathrm{~m}$.

(3) Secondary radius of curvature: $0.5 \mathrm{~m}$.

(4) Ideal shape tolerance: $0.2 \mathrm{~mm}$.

The mechanical characteristics of the material and behaviour laws will be defined later. Observing the large panel dimensions, it is obvious that classical stamping or deepdrawing presses cannot be employed for the forming. That is why a 50-ton Hufford press provided by the Airbus Industry has been modified in order to perform this study: punch grips, die support and numerical control of the displacements have been adapted to large panel manufacturing.

\section{Cold-forming process parameters}

\subsection{Process description}

The process cycle is defined by several sequences of stretching and drawing operations. In each sequence, the sheet is initially stretched to induce uniform plastic strains after what it is drawn on the die to take on the desired shape. The architecture of the drawing bench is sketched in Figure 2: it is built on the basis of the Hufford stretching press. On each side of the press, two hydraulic jacks draw the sheet metal in such a manner that they are auto-
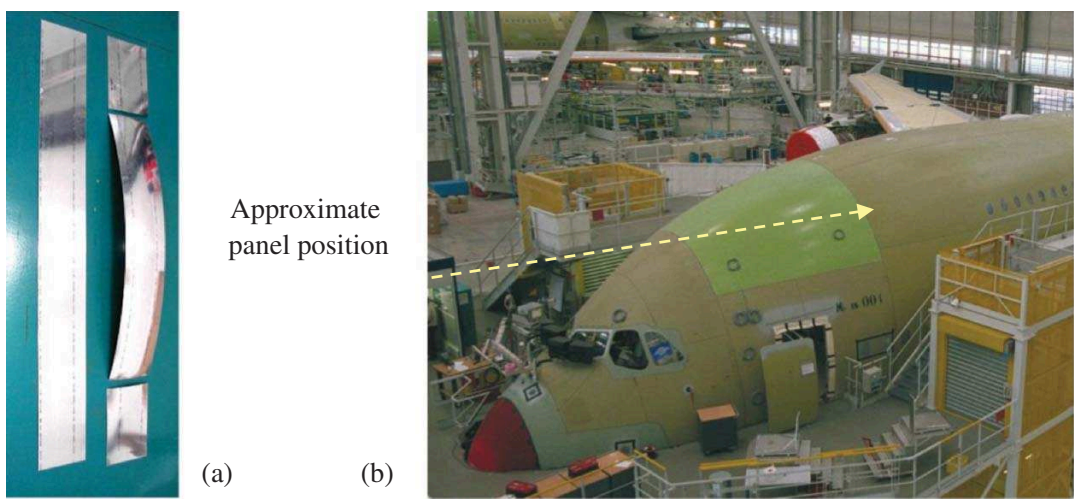

Figure 1. (a) Strip and formed part; (b) panels in the assembly zone. 




Figure 2. Sketch of the forming machine.

aligned with it at each instant. Two rotating arms allowing for the application of the sheet on the die are actuated by two other hydraulic jacks which complete the machine.

The initial Hufford press was redesigned in order to ascertain that the following performances were obtained:

- Maximum stretching force: $420 \mathrm{kN}$ (42 tons).

- Drawing speed: from $0.1 \mathrm{~mm} / \mathrm{s}$ to $1 \mathrm{~mm} / \mathrm{s}$.

- Tolerance of the die shape: $0.1 \mathrm{~mm}$.

- Maximum grip speed: $20 \mathrm{~mm} / \mathrm{s}$.

- Angular position of the arm: from $-10^{\circ}$ to $20^{\circ}$.

- Maximum angular velocity of the arms: $1 \%$ s.

- Maximum stretching strain $(A \% \max ): 10 \%$.

The forming die (Figure 3) is made of assembled wood panels with a main radius of curvature of $5 \mathrm{~m}$ and a secondary radius of curvature of $0.5 \mathrm{~m}$. The operational die dimensions are $1.500 \times 0.400 \mathrm{~m}^{2}$, and the outer surface was machined on a 5-axes milling centre with a dimensional tolerance of $0.01 \mathrm{~mm}$ everywhere on the surface. A sheet metal is shown in Figure $3 \mathrm{~b}$ in the process of stretching, drawn by the grips at each side.

The press was instrumented in order to measure the relative elongation $A \%$ and the rotation angles $\alpha_{R}$ of the right arm and $\alpha_{L}$ of the left arm (Figure 2) in view of managing the forming process. Some dissymmetry can appear in controlling both sides of the machine. But the machine is controlled to obtain the same rotation angle value for both arms: $\alpha_{R}=\alpha_{L}$. In the following, this rotation angle will be referred to as $\alpha$.

A cycle of the forming process is composed of successive incremental drawings and arm rotations which are sequentially piloted by a specific controller. Sequential drawings and rotations are not linked, but it was practically observed that the rotation of the arms generates a lengthening of the sheet at each step and must be accounted for the total sheet drawing. The machine cycle is thus made up of successive stretching operations (parameter $A \%$ ) and rotating motions (parameters $\alpha_{R}$ and $\alpha_{L}$ ). These parameters take different values during the forming process, as given in Table 1. Step 0 corresponds to the initial position with $\alpha_{R}=\alpha_{L}=-10^{\circ}$. At the beginning of Step1, the automat drives the sheet metal drawing until a percentage of lengthening about $1.2 \%$. The operator regulates the drawing force to control the drawing speed. When the percentage of lengthening is reached, the drawing operation stops and the rotation of the arms starts up to the value of the first rotation angle $\alpha_{R}=\alpha_{L}=0^{\circ}$. This sequence is then repeated in the other steps of the cycle.



(a)

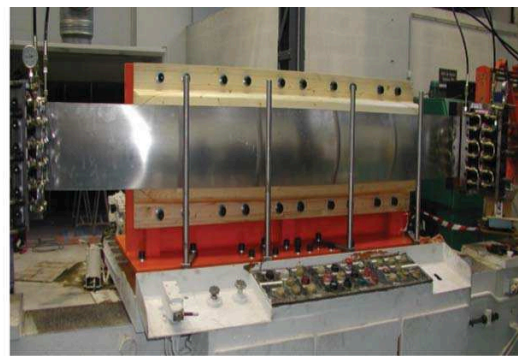

(b)

Figure 3. (a) Die shape; (b) sheet forming. 
Table 1. Forming sequences.

\begin{tabular}{lcccccrr}
\hline & Step 0 & Step 1 & Step 2 & Step 3 & Step 4 & Step 5 & Step 6 \\
\hline$A \%$ & $0 \%$ & $1.2 \%$ & $1.2 \%$ & $1.5 \%$ & $1.5 \%$ & $2 \%$ & $2 \%$ \\
$\alpha_{R}, \alpha_{L}$ & $-10^{\circ}$ & $-10^{\circ}$ & $0^{\circ}$ & $0^{\circ}$ & $10^{\circ}$ & $10^{\circ}$ & $20^{\circ}$ \\
\hline
\end{tabular}

\subsection{Process control}

The reference parameters for controlling the process are the stretching actuator displacements and the arm rotations. For each sequence, the stretching operation begins from the position reached in the previous drawing step where the sheet is tangential to the die.

In the first step of the study, the machine is sequentially controlled and positions are computed using numerical simulations on ABAQUS ${ }^{\circledR}$ FEM code, coupled to a CAD sketch analysis using CATIA $^{\circledR}$ (see Figure 3 ), in order to follow the history curve. The grips coordinates are computed as a function of the arms angles $\alpha$ and sheet stretching $A \%$.

The angular positions of the arms are detected by a rotating incremental transducer with a precision of $0.1^{\circ}$, and the sheet stretch is picked up by means of a large displacement cable transducer.

\subsection{Material parameters for cold-forming tests}

The tested material is a 2024 aluminium alloy (ISO Al $\mathrm{Cu} 4 \mathrm{Mg} 1$ ). Its mechanical characteristics have been identified by performing different tests on specimens, as defined in Figure 4b. A typical stress-strain curve, corresponding to a specimen with a thickness $t_{0}=2.5 \mathrm{~mm}$ machined in the rolling direction, is shown in Figure 4a.

Since this type of alloy is well known to exhibit some plastic anisotropy, several tests have been performed on specimens with a grain orientation in the rolling direction $\left(0^{\circ}\right)$ and in the transverse direction $\left(45^{\circ}\right.$ and $\left.90^{\circ}\right)$. Lankford coefficients (measured between $4 \%$ and $6 \%$ ) and material characteristics corresponding to the sheet metal behaviour are listed in Table 2. All parameters are the mean values of three tests performed in each direction.

An elastoplastic material behaviour law including plastic anisotropy was used in tabulated form in the numerical simulations when analysing springback effects and thickness evolution. A comparison between isotropic and anisotropic material behaviour has been performed to study the effect on forming and springback steps.

\section{Cold-forming tests}

The objective of these tests is to validate both numerical and experimental procedures in order to produce components with the required dimensional accuracy.





$t_{0}=2.5 \mathrm{~mm}$

(b)

Figure 4. 2024 aluminium alloy: (a) stress-strain uniaxial curve; (b) specimen.

Table 2. Mean values of 2024 aluminium alloy properties.

\begin{tabular}{lcccccc}
\hline & Lankford factors & Young's modulus (MPa) & Poisson factor & Yield stress (MPa) & $A \%$ & Rupture stress (MPa) \\
\hline Test at $00^{\circ}$ & $0.72 \pm 4 \%$ & 63,600 & 0.38 & 350 & 21 & 550 \\
Test at $45^{\circ}$ & $1.07 \pm 2.3 \%$ & 65,300 & 0.38 & 345 & 23 & 539 \\
Test at $90^{\circ}$ & $0.84 \pm 1.2 \%$ & 67,100 & 0.38 & 345 & 24 & 540 \\
\hline
\end{tabular}




\subsection{Basic continuum mechanics relationships}

The implementation of the continuum mechanics laws in the ABAQUS FEM code has been carried out on the basis of an elastoplastic material behaviour with plastic anisotropy, as defined in the AbaqusAnalysis User's manual (Hibbitt, Karlsson, Sorensen, Inc. 2011b). In sheet metal-forming applications, the usual assumption of plane stress state can be made, leading to two-dimensional simplified expressions. If there is no temperature effect, the uniaxial elastoplastic law for the 2024 aluminium alloy is written in the form of

$$
\sigma=\sigma_{u}-\left(\sigma_{u}-\sigma_{s}\right) \exp \left(-\alpha\left(\bar{\varepsilon}^{p l}\right)\right)
$$

where $\sigma_{u}$ and $\sigma_{s}$ are the ultimate and yield stresses, respectively, and $\alpha$ is a material parameter determined from the stress-strain tensile tests (Figure 4a). When planar anisotropy is accounted for, Hill's anisotropy plasticity potential (Hill 1990) can be expressed in terms of rectangular Cartesian stress components as

$f(\sigma)=\sqrt{F\left(\sigma_{22}-\sigma_{33}\right)^{2}+G\left(\sigma_{33}-\sigma_{11}\right)^{2}+H\left(\sigma_{11}-\sigma_{22}\right)^{2}+2 N \sigma_{12}}$

This expression results from the plane stress assumption involving $\sigma_{23}=\sigma_{31}=0$ when the axis 3 is normal to the plane of the sheet. Considering $l$ as the rolling direction $\left(0^{\circ}\right)$ and $c$ as the cross-direction $\left(90^{\circ}\right)$, the incremental strain ratios $r_{l}$ and $r_{c}$ are defined as follows:

$$
r_{l}=\frac{d \varepsilon_{11}}{d \varepsilon_{33}} r_{c}=\frac{d \varepsilon_{22}}{d \varepsilon_{33}}
$$

It is shown in Hibbitt, Karlsson, Sorensen, Inc. (2011b) that the material coefficients $F, G, H$ and $N$ are related to the non-dimensional coefficients $R_{22}, R_{33}$ and $R_{12}$ defined by the following expressions:

$$
\begin{aligned}
R_{11}=1 \quad R_{22} & =\sqrt{\frac{r_{c}\left(r_{l}+1\right)}{r_{l}\left(r_{c}+1\right)} \quad R_{33}=\sqrt{\frac{r_{c}\left(r_{l}+1\right)}{\left(r_{c}+r_{l}\right)}}} \\
R_{12} & =\sqrt{\frac{3 r_{c}\left(r_{l}+1\right)}{\left(2 r_{45 \circ}+1\right)\left(r_{c}+r_{l}\right)}}
\end{aligned}
$$

where $r_{45^{\circ}}$ is the Lankford coefficient in direction at $45^{\circ}$ regarding the rolling direction. For the 2024 aluminium alloy, the $R_{i j}$ coefficients are computed with the values given in Table 1, which leads to the following values:

$$
R_{11}=1, R_{22}=1.044, R_{33}=0.962 \text { and } R_{12}=0.9406
$$

Inserting $R_{i j}$ in the flow Equation (2) allows the incremental computation of strains and stresses. The reader is referred to Hibbitt, Karlsson, Sorensen, Inc. (2011b) for a more detailed development of calculations.

\subsection{Contact conditions}

Various experiments have revealed that a friction phenomenon arises between the sheet metal and the wooden die so that this phenomenon cannot be ignored. When the stretching begins, there is a low normal force at contact inducing a low tangential force and then the sheet slides with friction on the die. Then, when the arms rotate, the normal force increases strongly and, resulting from friction, the sheet cannot slide easily on the central zone of the die.

In order to characterise the wood/metal contact during the forming operation and to evaluate the friction coefficient value $\mu$, an inverse method implying comparisons between numerical simulations and experimental results has been carried out. Testing different contact models and varying the values of $\mu$ from 0.1 to 0.5 , it has been found that a coulomb friction model with an average value of $\mu=0.3$ gives satisfactory results: simulations match experiments. The comparisons have been performed on the deformed shapes and the in-plain strains. The deformed shapes have been compared by surface analyses with CATIA according to the adjustment loop presented in Figure 8. The in-plain strains have been measured by using a square mesh drawn on a sheet of 2024 T4-HF with an initial thickness $t_{0}$ equal to $1.6 \mathrm{~mm}$. The results are illustrated in Figure 5: the major influence of friction on the strain distribution is shown. Due to symmetry of the stretching process, it can be noted that the strains are null in the middle zone of the sheet. It is also obvious that the material is increasingly stretched when getting closer to the grips where there is no contact between the sheet and the die.

\subsection{Numerical simulation}

\subsubsection{Finite element modelling}

The finite element model describes a half side of the machine, taking account of the loading symmetry of the system. An implicit scheme is used to simulate the full cycle: forming steps and springback phase. A preliminary sensitivity analysis has been carried out to choose appropriate elements, mesh size and element options. The following ones have been retained:

- For the sheet, linear shell elements with reduced integration and default hourglass control with seven integration points in the thickness (S4R element in ABAQUS) have been chosen. After the preliminary tests, a mesh size ranging from 8 to 12 elements in the width gives a good compromise between convergence, precision and CPU time (see 




Figure 5. Experimental $(\mathrm{a}, \mathrm{b})$ and numerical $(\mathrm{c}, \mathrm{d})$ strain distribution in the sheet $\left(2024 \mathrm{~T} 4-\mathrm{HF} t_{0}=1.6 \mathrm{~mm}\right)$.

Table 3). Figure 6 shows a model meshed with an average edge size of $40 \mathrm{~mm}$ corresponding to 8 elements in the width and 40 in the half-length.

- For the die, rigid body assumption was made with small elements of $4 \mathrm{~mm}$ refined in the round edges to avoid tearing of the sheet on sharp angles.

\subsubsection{Boundary conditions}

Once the die and the sheet meshed, the latter is slightly brought down to correctly contact the die. Symmetry is used to model only one half of the parts and then the nodes in the plane of symmetry are blocked, as well as the reference point of the die. The drawing load is applied on the opposite side of the sheet in the form of a uniform pressure which evolves according to the aforementioned sequential stretching and bending operations. At the end of the process, the pressure is set to zero in order to let the springback take place.

\subsubsection{Contact representation}

The sliding interface between die and sheet metal is based on master and slave surfaces. The master surface generally belongs to the non-deformable body as the die in the present case, and the slave surface belongs to the deformable body, here the sheet. A measure of the over closure is constructed at each eventual point where the slave node might penetrate into the master surface and introduced in an augmented energy functional. A Lagrange's multipliers technique is applied in view of minimising the functional in order to manage the contact simulation. Newton computation scheme is then carried out in order to satisfy all mechanical equations. The interaction contact model uses

Table 3. Sensitivity analysis of mesh size.

\begin{tabular}{llllll}
\hline Mesh average size $(\mathrm{mm})$ & $10 \mathrm{~mm}$ & $20 \mathrm{~mm}$ & $30 \mathrm{~mm}$ & $40 \mathrm{~mm}$ & $60 \mathrm{~mm}$ \\
\hline Max in-plane strain $\varepsilon_{\mathrm{xx}}$ & 0.0487 & 0.0487 & 0.0488 & 0.0485 & 0.0549 \\
CPU time (min) & 30 & 15 & 10 & 8 & 5 \\
\hline
\end{tabular}

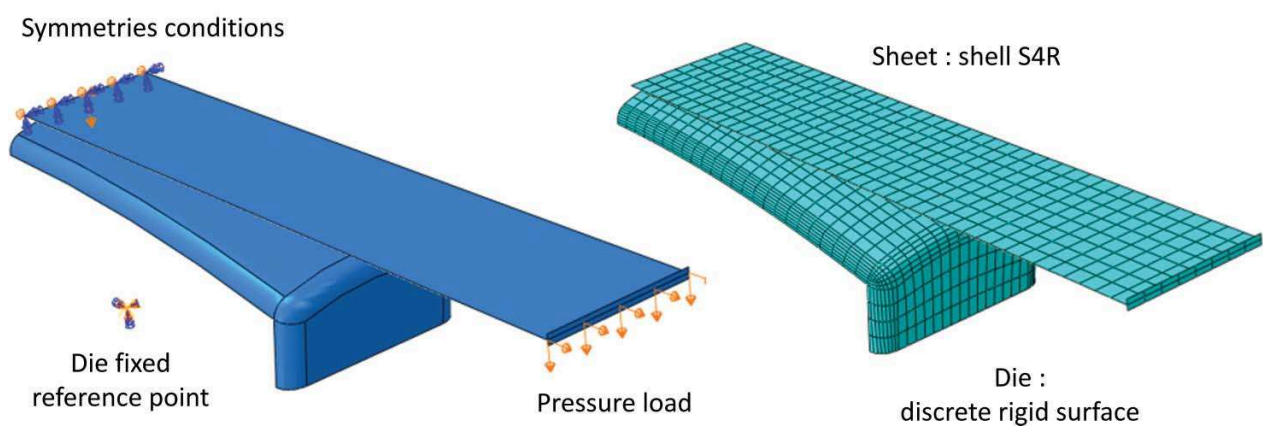

Figure 6. Mesh and boundary conditions. 
a 'surface to surface' control, with master surface smoothing and no allowable interference and adjustment of slave surface only to remove over closure. The implicit step solver option for matrix storage is asymmetric. The tangential contact behaviour is modelled by isotropic Coulomb friction.

\section{Experimental procedure for sheet digitalisation}

To check if numerical simulations give accurate results, the surface of the computed stretched sheet is compared to the experimental ones. As the numerical simulation allows obtaining a CAD model of the internal surface of the stretched sheet, the objective of the experimental procedure is to recover the CAD model of the real deformed sheet. This is achieved by using a digitalisation machine of company $\mathrm{GOM}^{\circledR}(\mathrm{GOM} \mathrm{mbH}$ - Gesellschaft für Optische Messtechnik, Braunschweig, Germany). In order to perform a correct digitalisation, the following stages were carried out:

- Powdering of the surface in order to avoid sheet reflection.

- Installation of self-adhesive stickers as reference points on the sheet surface.

- Calibration of the machine controller.

- Digitalisation measurements.

- Meshing and export of the dots cloud from the digitalised surface.

A representation of the machine test and experimental procedure is given in Figure 7 . The powdered sheet reflects the projector rays, and two cameras register the spatial position of the surface points by a triangulation method.

The $\mathrm{GOM}^{\circledR}$ software makes it possible to compare the relative positions of two digitalised surfaces, and this was applied here in order to evaluate the differences between the real sheet shape and the one predicted by numerical simulation.

The overall error results from the GOM machine tolerance induced by the digitalisation operation and the accuracy of the CAD surface representation. In the first case, a value of $0.056 \mathrm{~mm}$ and, in the second case, a value of $0.158 \mathrm{~mm}$ were found, leading to an overall error of $0.214 \mathrm{~mm}$.

\section{Model calibration procedure}

The numerous experiments carried out on the forming machine have shown that there are a lot of parameters which influence the resulting shape of the formed part. A solution to avoid fluctuating variations of the physical parameters during the forming operation consists in automatically adjusting simulation to experiment. This is achieved by developing an optimisation strategy of the numerical simulation.

\subsection{Optimisation strategy}

The optimisation strategy described in Figure 8 uses experimental and numerical feedback loops to adjust the process parameter values in the simulation in view of optimising the die shape compared to the experimental results.

The finite element simulations coupled to the trajectory control on the CAD system will serve to find optimal sets of parameters (optimal die shape, motion and force controls) which lead to the desired 'exact' panel shape. The proposed protocol uses two sequential loops, the first to realise the adjustment of the numerical model and the second to determine the optimal parameters. In the first loop, the adjustment has been realised by comparing the numerical deformed shape with the formed sheet obtained experimentally on the instrumented Hufford bench. The comparison procedure uses surface analysis


Sketch for computing shape difference between two digitalised surfaces

Figure 7. Experimental sheet surface digitalisation procedure. 


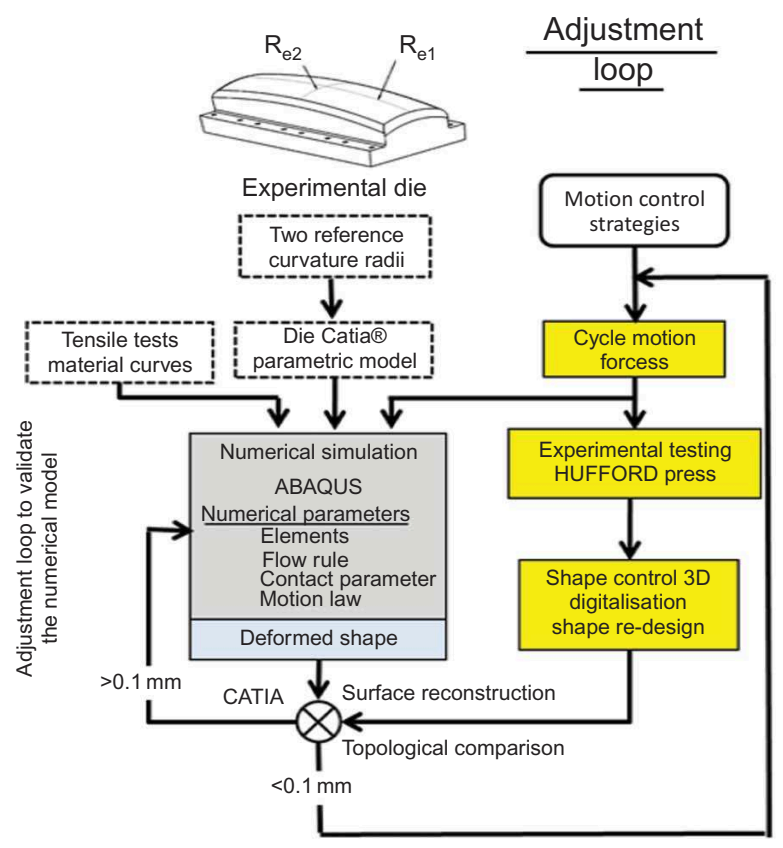

(a)

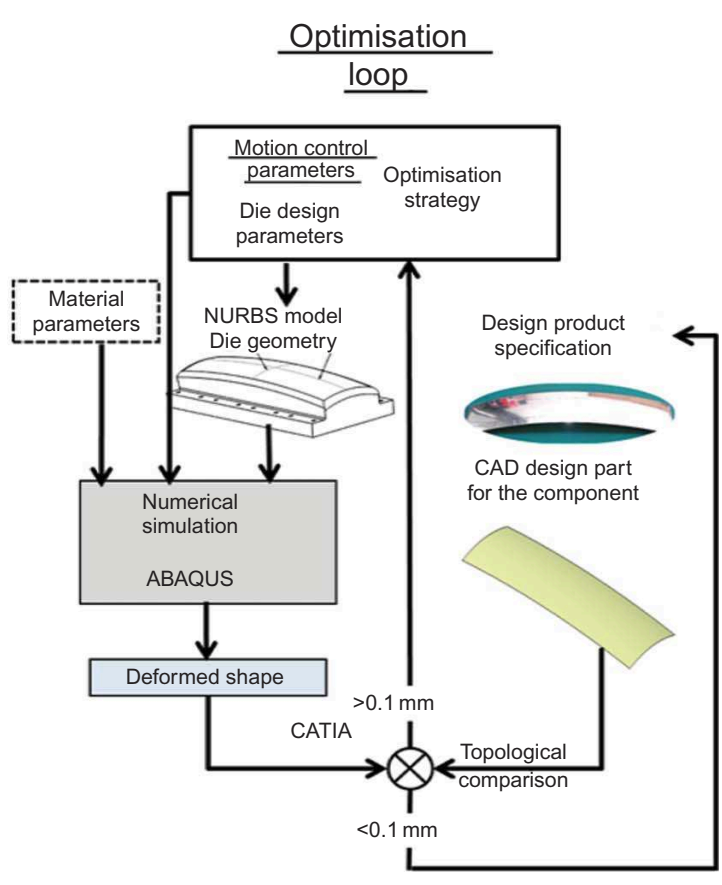

(b)

Figure 8. (a) Numerical-experimental calibration algorithm; (b) optimisation loop.

tools integrated in the CAD software CATIA ${ }^{\circledR}$ and 3D scanning coupled to redesign techniques, as shown in Figure 7. The numerical deformed shape has been imported from ABAQUS ${ }^{\circledR}$ into the CAD system as a cloud of points.

\section{Results of numerical simulation}

\subsection{Forming operations}

The sequential operations simulating the different steps of experimental process have been performed with an implicit scheme on ABAQUS. The simulation of the springback has been realised in two major steps: first by decreasing progressively the pressure loads on the grips and second by moving the die out of the deformed shape. Deformation representations for the aluminium alloy 2024 sheets are presented in Figures 10a and 10b.

The design of the grips allows squeezing the edges of the sheet between two, flat, thick steel plates in order to act on the sheet. This is illustrated in Figure 9. In turn, that device prevents the sheet curvature at the ends, and sufficient materials are needed to ensure a satisfactory shape. To limit such disadvantage, the sheet length is about $50 \mathrm{~cm}$ at each side longer than the useful formed part.

\subsubsection{Elastic springback evaluation}

Tests have been carried out on the Hufford machine with an aluminium sheet with a thickness of $1.6 \mathrm{~mm}$. By comparing the geometry of the stretched sheet with that of the die, the value of the elastic springback has been quantified. A maximum shape deviation of $10.7 \mathrm{~mm}$ and an average variation of $6.7 \mathrm{~mm}$ have been obtained, as illustrated in Figure 10a.

The simulated value of the elastic springback has been obtained by comparing the surface position of a sheet at the end of the loading stage with the final shape of the sheet after stress relaxation. This comparison gives a maximum shape deviation of $9.3 \mathrm{~mm}$ and an average variation of $6.7 \mathrm{~mm}$ in the case of simulation with an isotropic material behaviour, as illustrated in Figure 10b.

Observation of the two springback repartitions shows that the numerical prediction is very close to the real sheet's shape but that this one is far from the expected one. A solution based on simulation accuracy would allow for a new die geometry definition accounting for the final springback in order to form the aircraft panels as closely as possible. Nevertheless, this solution must be developed by accounting for the real material behaviour.

\subsubsection{Influence of material anisotropy}

The sheet anisotropic behaviour has been defined in Table 1 from which it can be noticed that the ratio $\frac{r_{90^{\circ}-r_{0}}}{r_{00^{\circ}}}$ of the Lankford coefficients between cross and rolling directions is about $14 \%$. Such a value implies that the sheet anisotropy must be accounted for in 


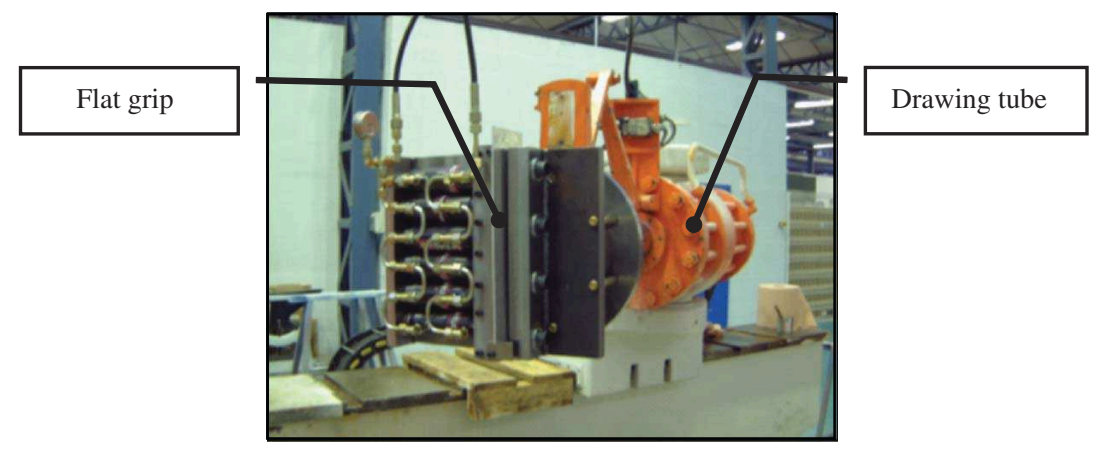

Figure 9. Flat grips of the stretching machine.
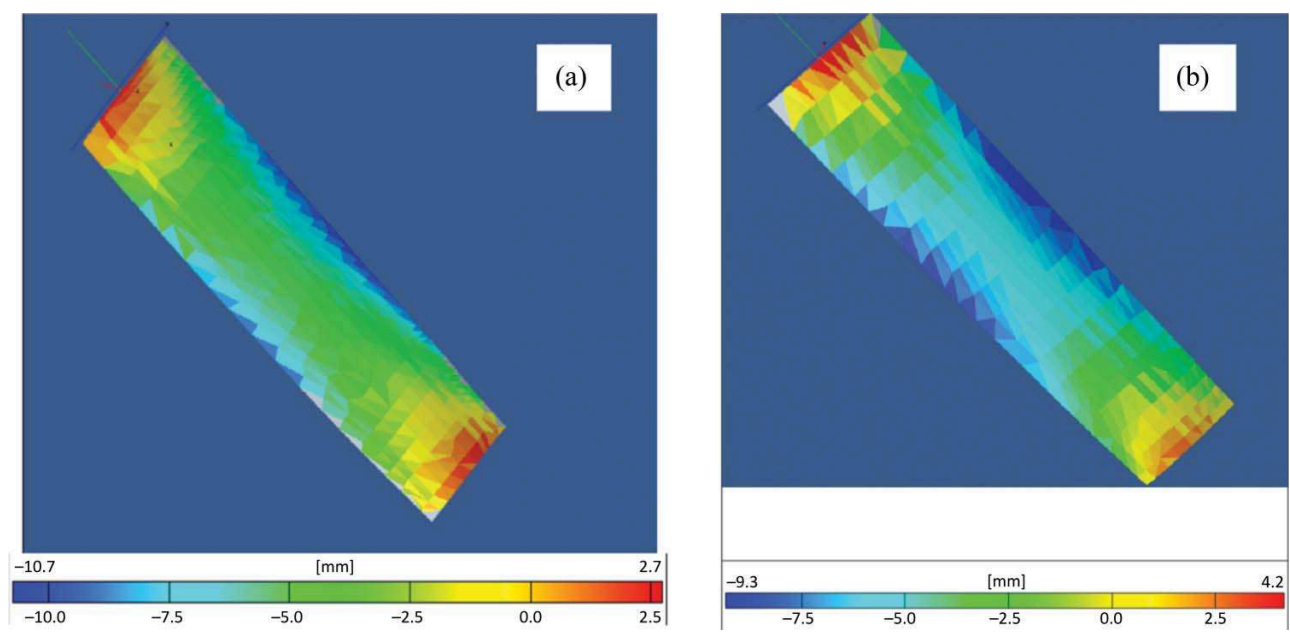

Figure 10. Elastic springback repartition. (a) Experimental; (b) simulation.

numerical simulations. So, various simulations, including or not anisotropic formulations, have been performed: it was found that the corresponding numerical results are very close to one an other. Consequently, it can be concluded that the material anisotropy does not strongly influence the final shape of formed 2024 aluminium sheets. Isotropic formulations may therefore be used in simulations. An illustration of the difference resulting from the two formulations (isotropic and anisotropic) is given in Figure 11. The initial sheet thickness is $t_{0}=2.5 \mathrm{~mm}$. It can be noted that the shape difference does not exceed $0.34 \mathrm{~mm}$ with a mean value of $0.26 \mathrm{~mm}$ measured on a sheet with dimensions $900 \times 270 \mathrm{~mm}^{2}$.

\subsubsection{Influence of sheet thickness}

The influence of the sheet thickness has been studied by comparing the deformed shapes obtained for sheets with an initial thickness of 1.6 and $2.5 \mathrm{~mm}$. The same loading conditions as the ones given in Table 1 have been chosen for each studied thickness. It has been observed that the sheet with thickness $2.5 \mathrm{~mm}$ does not perfectly match the die shape at the end of forming. The maximum shape deviation between the final formed sheet and the die

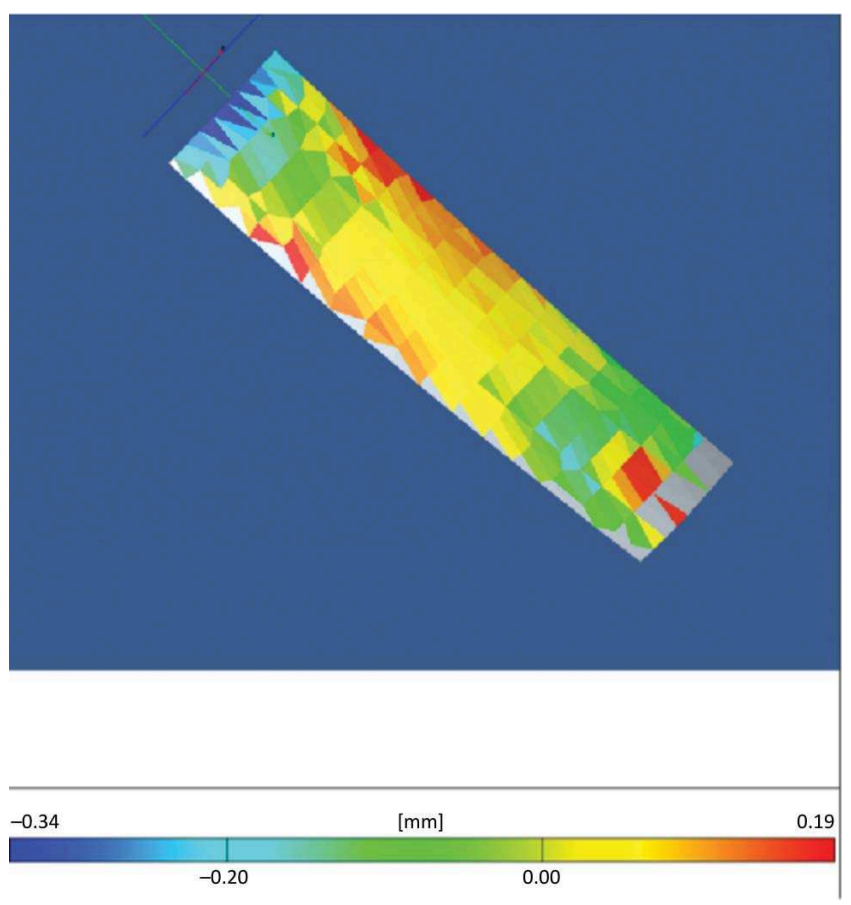

Figure 11. Displacement differences between anisotropic and isotropic formulations. 
does not exceed $1.5 \mathrm{~mm}$. For the $1.6 \mathrm{~mm}$ sheet, the average measured deviation ranges from 7 to $9.5 \mathrm{~mm}$.

It can be concluded that the initial sheet thickness is a major parameter of the process and that it is important to choose the appropriate loading cycle to ensure that the whole sheet correctly matches the die shape at the end of the forming step.

\section{Conclusion}

The manufacturing of aeronautic panels by cold stretching is a complex operation due to the machine design and material behaviour identification. Due to large dimensions of such parts, there are no economical concurrent methods applicable to their forming and there is an obvious industrial need to deal with cold stretching.

It is necessary to develop a numerical protocol to design the die shape and to control the loading evolution during the forming cycle in view of obtaining reproducible operations and to produce aeronautic panels according to the functional design. In this work, an accurate numerical protocol has been developed by using 3D scanning and redesign tools in view of the experimental analysis of deformed aluminium 2024 panels obtained by a stretching cold-forming process. An adjustment loop has been carried out by comparing the experimental deformed shape and the one obtained by numerical simulations on ABAQUS. The results show a good agreement between numerical and experimental data. This study has allowed identifying the major parameters of the cycle: sheet initial thickness, loading sequences, material flow rule and die shape. In future works, the optimisation loop will be used to choose the best configurations of parameters to design the die shape and predict the loading in order to respect the functional design specifications of the product. The same method will also be used for the sheet forming by stretching at higher temperatures.

\section{References}

Chien, W. Y., J. Pan, and S. C. Tang. 2004. "A Combined Necking and Shear Localization Analysis for Aluminium Sheets Under Biaxial Stretching Conditions." International Journal of Plasticity 20: 1953-1981.

Ding, S. C., and J. L. Duncan. 2004. "Instability in BendingUnder-Tension of Aged Steel Sheet." International Journal of Mechanical Sciences 46: 1471-1480.

He, D. H., D. S. Li, X. Q. Li, and C. H. Jin. 2010. "Optimization on Springbackreduction in Cold Stretch Forming OftitaniumAlloyaircraft Skin China." Transaction of Nonferous Metals Society of China 20: 2350-2357.

Hibbitt, Karlsson, Sorensen, Inc. 2011a. ABAQUS®/Standard User's Manual. Pawtucket, RI: Hibbitt, Karlsson \& Sorensen.

Hibbitt, Karlsson, Sorensen, Inc. 2011b. ABAQUS® Analysis User's Manual. Pawtucket, RI: Hibbitt, Karlsson \& Sorensen.

Hill, R. 1990. "Constitutive Modelling of Orthotropic Plasticity in Sheet Metals." Journal of Mechanics and Physics of Solids 38 (3): 405-417.

Meinders, T., I. A. Burchitz, M. H. A., Bonte, and R. A. Lingbeek. 2008. "Numericalproduct Design: Springback Prediction, Compensation and Optimization." International Journal of Machine Tools and Manufacture 48 (5): 499-514.

Naceur, H., Y. Q. Guo, and S. Ben-Elechi. 2008. "Response Surface Methodology for Design of Sheet Forming Parameters to Control Springback Effects." Computers and Structures 84: 1651-1663.

Pourboghrat, F., and E. Chu. 1995. "Springback in Plane Strain Stretch/Draw Sheet Forming." International Journal of Mechanical Science 36 (3): 327-341.

Yoshida, M., F. Yoshidab, H. Konishia, and K. Fukumoto. 2005. "Fracture Limits of Sheet Metals Under Stretch Bending." International Journal of Mechanical Sciences 47: 18851896. 